\title{
Frames en 280 caracteres: un estudio sobre el proceso de incorporación de los marcos propuestos por Folha Online y Estadão. com en los posts de las audiencias en Twitter
}

\section{Frames in 280 characters: a study on the incorporation process of the frames}

proposed by Folha Online and Estadão.com in the posts of their audiences on Twitter
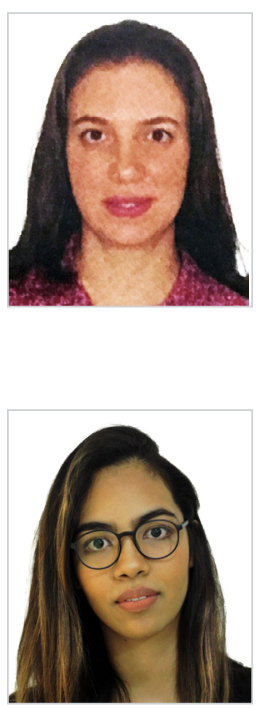

Carla Tonetto Beraldo. Licenciada en Comunicación Social (Pontifícia Universidade católica - PUC), especialista en Edición por la Escola de Comunicação Social Cásper Líbero y estudiante de Máster en el Programa de Posgrado en Comunicación y Cultura Contemporánea de la Universidad Federal de Bahía (UFBA - Brasil). En la actualidad, es miembro del Grupo de Periodismo en Línea (GJOL), pionero en Brasil; este grupo lleva desde 1995 trabajando en el campo del periodismo en redes digitales y nuevas tecnologías de la comunicación, investigando la accesibilidad de los medios digitales y la responsabilidad de los periodistas en la generación de contenidos inclusivos. Investiga la interacción entre la tecnología y el periodismo. Las redes han cambiado los principios clásicos del periodismo. Tiene un máster del Consejo Nacional de Desarrollo Científico y Tecnológico (CNPq).

Universidade Federal da Bahia (UFBA), Brasil

carla.beraldo@ufba.br

ORCID: 0000-0002-1526-0265

Alix del Carmen Herrera. Comunicadora Social y Periodista, con enfoque en comunicación para el desarrollo social (Universidad Minuto de Dios, Colombia); Master en Comunicación y Cultura Contemporánea (Universidad Federal da Bahia, Brasil) y miembro del Grupo de Investigación en Periodismo Online (GJOL) desde 2019. Desarrolla un proyecto de investigación sobre la relación con las audiencias dentro de los medios que utilizan las membresías como modelo de negocio y editorial. Es becaria del Consejo Nacional de Desarrollo Científico y Tecnológico (CNPq), Brasil.

Universidade Federal da Bahia (UFBA), Brasil

alix.herrera@ufba.com.br

ORCID: 0000-0002-6745-3835

Recibido: 20/08/2020 - Aceptado: 14/03/2021 - En edición: 11/04/2021 - Publicado: 14/06/2021

\section{Resumen:}

Este artículo tiene como objetivo buscar relaciones entre los discursos de Folha Online y Estadão.com y los discursos en los posts de sus audiencias en la red social, Twitter, entorno a un evento político polémico, que tuvo lugar en Brasil en 2019. La discusión surge en un contexto marcado por afectos políticos, establecidos fuertemente
Received: 20/08/2020 - Accepted: 14/03/2021 - Early access: 11/04/2021 - Published: 14/06/2021

\section{Abstract:}

This article aims to seek connections between the discourses of Folha Online and Estadão.com and the discourses in the posts of their audiences on Twitter around a controversial political event which took place in Brazil in 2019. The discussion arises in a context marked by political affections, strongly established within the

Cómo citar este artículo:

Tonetto Beraldo, C. y Herrera, A. C. (2021). Frames en 280 caracteres: un estudio sobre el proceso de incorporación de los marcos propuestos por Folha Online y Estadão.com en los posts de las audiencias en Twitter Doxa Comunicación, 32, pp. 405-430.

https://doi.org/10.31921/doxacom.n32a19 
en el pueblo brasileño después de episodios controvertidos y ampliamente divulgados por la prensa, que van desde una desconfianza general en los medios de comunicación hasta una defensa enérgica de las posiciones políticas individuales. Adoptando una metodología cualitativa y cuantitativa utilizamos palabras clave como unidades de análisis y consideramos tanto la frecuencia en el uso de palabras como la función de encuadramiento que cada una ejerce. Los resultados muestran una relación entre los frames propuestos por la prensa y los utilizados por el público, pero estos varían según cada función sugerida por Entman (1993).

\section{Palabras clave:}

Encuadramiento; Twitter; discurso mediático; redes sociales.
Brazilian people after controversial episodes widely reported by the press, ranging from a general mistrust of the media to an energetic defense of individual political positions. Adopting a qualitative and quantitative methodology, we use keywords as units of analysis, and consider both the frequency in the use of those words and the framing function that each one exerts. The results show a relationship between the frames proposed by the media and those used by the audience, but these vary according to each function suggested by Entman (1993).

\section{Keywords:}

Framing; Twitter; media discourse; social media.

\section{Introducción}

Hoy, gran parte de lo que los brasileños conocen sobre política proviene de las redes sociales. Según el Reuters Institute Digital News Report 2020, es la primera vez, desde el 2013, que las redes sociales superan a la televisión como medio para el consumo de noticias en el país (Newman et al., 2019). Así, los espacios digitales ahora son un lugar común y obligado para el periodismo, desde donde se propone brindar interpretaciones del mundo (Brüggemann, 2014) a la opinión pública.

Este punto coincide con la idea inicial del Framing o encuadramiento, ${ }^{1}$ cuya perspectiva analiza la manera como los medios de comunicación presentan un hecho específico en sus reportajes, y dan relevancia u omiten determinadas informaciones. En 1922, Walter Lippman, en su trabajo Public Opinion, mencionaba la esencia del modelo: “[...] los medios de comunicación, nuestra ventana al vasto mundo más allá de nuestra experiencia directa, determinan nuestros mapas cognitivos del mundo" (McCombs \& Reynolds, 2002, p. 2). De manera más puntual, "la lógica central del framing es que los periodistas construyen representaciones simbólicas de la sociedad que el público utiliza para dar significado a los eventos y problemas" (Bronstein, 2005, p. 785). Siguiendo ambas perspectivas, reconocemos a las palabras clave como símbolos ${ }^{2} \mathrm{y}$ unidades de significado que son transmitidas a través de los mensajes periodísticos.

En ese sentido, los estudios sobre encuadramiento han privilegiado una “[...] perspectiva mediacéntrica [...]. En la que, la actividad mediática en sí misma se convierte en objeto y eje central de estos estudios” (López, 2010). Dicho de otra forma, las investigaciones sobre encuadramiento se han centrado en la manera en la que los medios construyen los marcos y, en menor medida, cómo estos son inseridos en los contextos sociales, incluso cómo frames propuestos por otro tipo de organizaciones (e.g. grupos políticos, movimientos sociales) son adoptados por los medios.

1 En este artículo, los términos framing y encuadramiento se refieren a la hipótesis de los efectos de los medios y serán utilizados como sinónimos

2 Para mayor precisión, adoptamos la definición dada por la Real Academia Española como "forma expresiva que introduce en las artes figuraciones representativas de valores y conceptos, y que a partir de la corriente simbolista, a fines del siglo XIX, y en las escuelas poéticas o artísticas posteriores, utiliza la sugerencia o la asociación subliminal de las palabras o signos para producir emociones conscientes" REAL ACADEMIA ESPAÑOLA: Diccionario de la lengua española, 23. ${ }^{\text {a }}$ ed., [versión 23.4 en línea]. <https://dle.rae.es> [10 marzo de 2021]. 
Teniendo esto en mente, el propósito de este artículo es comprender el funcionamiento de los frames propuestos por los periódicos Folha Online y Estadão.com con relación al recorte de fondos a la educación superior realizados por el gobierno brasileño en 2019. De esta manera, buscamos entrever si tales frames fueron recibidos por sus audiencias e incorporados en sus discursos en Twitter; asimismo, pretendemos verificar qué aspectos fueron resaltados frecuentemente. Además, nuestro análisis considera el contexto de polarización política desatada en los primeros seis meses de gobierno del actual presidente de Brasil, Jair Bolsonaro. En el cual, destacamos las medidas adoptadas por el Ministerio de Educación (MEC), las cuales fueron objeto de varias controversias que llamaron la atención de los medios de comunicación y la opinión pública.

Durante el periodo mencionado, las decisiones del MEC estuvieron marcadas por debates frente a hechos como los cambios en el cuerpo directivo de la entidad, el recorte de los fondos destinados a las universidades federales, los problemas con el Instituto Nacional de Estudios e Investigación Educativa Anísio Teixeira (INEP), las tensiones ante el vencimiento del contrato, en 2020, del Fondo para el Mantenimiento y Desarrollo de la Educación Básica y Valorización de los Profesionales de la Educación (FUNDEB), entre otras polémicas. Mientras se desarrollaba esta investigación, el economista Abraham Weintraub era el segundo ministro encargado del MEC desde el inicio del nuevo gobierno; el primer titular fue Ricardo Vélez Rodríguez. El escenario, marcado por la restricción de gastos, así como por declaraciones y posiciones opuestas entre la opinión pública, aumentó el desgaste entre el gobierno y la oposición, por lo tanto, este trabajo se llevó a cabo en dicho contexto de "alta temperatura" política. En esta indagación, concentramos el análisis alrededor del recorte de fondos a las universidades federales, “[...] ya que cada temática tiene su dinámica de tiempo. Examinar más de un tema a la vez puede ser problemático" (Eyal, Winter \& De George, 1981, p. 216).

$\mathrm{Al}$ enfocarnos en los frames utilizados por Folha Online y Estadão.com en los artículos publicados sobre el tema y compartidos en Twitter -además de la aceptación de estos frames en los comentarios del público en la misma plataforma-, pretendemos avanzar en la comprensión de los frames transmitidos en estas publicaciones e identificar los aspectos destacados por la prensa y replicados por los lectores en sus tuits. Dada la importancia de los encuadramientos en la comunicación política, también examinamos si los frames identificados cumplen alguna de las cuatro funciones principales indicadas por Entman (1993): definición de problemas específicos, interpretación causal, evaluación moral y recomendación de tratamiento para el tema descrito.

Para realizar la investigación, recopilamos artículos y post de las cuentas oficiales de los periódicos en Twitter, relacionadas con el recorte de fondos a las universidades federales. El período seleccionado fue del 30 de abril de 2019, cuando se anunció la medida, al 30 de junio del mismo año. Según Wolf (2012, p. 175), “[...] los asuntos varían en relación al tiempo necesario para colocarlas en una posición relevante en la opinión pública”. Por lo que, optamos por un período de dos meses para la recopilación de datos; un intervalo suficiente para la consolidación de un debate público. De acuerdo con algunos elementos de la propuesta metodológica de Zhou y Moy (2007), confrontamos los frames de los medios y los frames en las respuestas de la audiencia, a partir de la selección de palabras clave, resultante de la búsqueda en la plataforma mediante de la herramienta TweetDeck, en el período delimitado para el análisis. 
Al final del texto, presentamos los resultados sobre la aceptación de los frames propuestos por los medios de comunicación, en los discursos del público en una plataforma como Twitter, en el marco de una situación con las condiciones necesarias para generar un amplio debate. También discutimos las implicaciones en el contexto brasileño, las variables en cada periódico y las posibilidades de los estudios sobre encuadramiento y algunas de sus particularidades en los debates públicos digitales.

\subsection{Fundamentación teórica}

Las investigaciones en el campo de la comunicación plantean varios problemas conceptuales y metodológicos, al tiempo que proponen soluciones a problemas específicos mediante la integración de diversas disciplinas (França, 2012). Precisamente los estudios sobre media effects reúnen desafíos epistemológicos que pertenecen al campo de la comunicación. En particular, es necesario comprender las perspectivas teóricas heterogéneas que "[...] se alternan, coexisten y se complementan" (Wolf, 2012, p. 137) en la discusión académica sobre encuadramiento.

Con base en esa multiplicidad, es una condición sine qua non abordar la hipótesis del establecimiento de la agenda (agenda setting) y revisar los límites teóricos de la relación entre framing y agenda setting, para entonces contextualizar sus superposiciones y explicar las particularidades de cada perspectiva. Ciertamente tratarlos de manera separada responde al hecho de que "[...] el encuentro de estos estudios [...] ha generado conclusiones contradictorias sobre el poder de los frames de los medios en la audiencia y el establecimiento de temas en la agenda del público” (Colling, 2001, p. 92). De acuerdo con Scheufele (2000), existen diferencias sustanciales entre ambos conceptos,

[...] dado que el establecimiento de la agenda funciona bajo un enfoque causal, en el que la frecuencia y la cantidad de veces con la que un tema es divulgado por los medios, interfiere en su posición en la agenda pública y, por lo tanto, el diseño y los métodos aplicados en estos estudios son aptos para comprender esta correlación causal (p. 46).

La perspectiva de que los medios seleccionan los temas que sobresalen en la opinión pública representa el primer nivel del establecimiento de la agenda (se refiere a objetos, es decir, la elección de temas que serán noticia). En el segundo nivel, también llamado establecimiento de atributos, ${ }^{3}$ el enfoque se centra en cómo estos temas se presentan al público en diferentes momentos. Si bien el establecimiento de la agenda está relacionado con el concepto contemporáneo de framing, no es posible suponer que este último está contenido en el primero. En palabras de Rossetto y Silva "[...] el framing enriquece la investigación de los efectos de los medios, especialmente el establecimiento de la agenda, sin embargo, a menudo se confunde con su segunda dimensión” (Rossetto \& Silva, 2012, p. 99).

De ahí que, siendo constante y desatinadamente sugerido como sinónimo del segundo nivel de establecimiento de la agenda, se hace necesario una delimitación clara del concepto de framing que atiende al propósito de este artículo. Primero, entendemos que el encuadramiento es la forma en que los hechos son interpretados en una noticia. Al respecto, Carragee y Roefs (2004) problematizan la reducción del framing a temas y atributos por dos razones principales: primero, esta perspectiva no tiene en cuenta la forma en que ciertos frames se aplican a diferentes temas; segundo, ignora cómo la

3 En la Teoría de Agenda-Setting, atributo es un término genérico que abarca la amplia gama de propiedades e indicadores que caracterizan un objeto (McCombs, 2004, p. 113). 
postura de un único sujeto puede ser producto de más de un frame. Preferimos por lo tanto, el enfoque dado por Erving Goffman.

Asumo que las definiciones de una situación se construyen de acuerdo con los principios de organización que rigen los eventos -al menos sociales- y nuestra implicación subjetiva en ellos; frame es la palabra que utilizo para referirme a esos elementos básicos que puedo identificar. Esa es mi definición de frame (Goffman, 1986, p. 10-11).

A partir de ahí, los frames estructuran qué fragmentos de la realidad pueden convertirse en noticias (Koenig, 2004). Así pues, el establecimiento de la agenda se refiere a la selección y destaque en los artículos publicados (objeto), mientras que el encuadramiento se refiere a la selección y destaque de los términos publicados (atributos de la publicación) (Scheufele, 1999).

Por lo que supone un proceso interpretativo que parte según Wolf (2011) "de la 'imposición' de un marco interpretativo de aquello que se ha cubierto intensamente" (p.117). El académico explica que el análisis de marcos o frames “[...] se incorporó a los estudios en periodismo y dio como resultado la actual hipótesis del encuadre o framing”. En la que según Park (2003), la prensa es responsable de construir una cierta comprensión de la realidad que funciona como el marco de una ventana. Metafóricamente, es por medio de ella que la opinión pública entrará en contacto con una realidad dada -parcial o no- y este contacto dependerá del tamaño de la apertura de dicha ventana (apud Leal, 2007, p. 145).

Metodológicamente, en una revisión bibliográfica, Pozobon y Schaefer (2014, p. 157) identifican dos puntos críticos relacionados con las investigaciones sobre framing. “[...] incertidumbre conceptual y falta de sistematización metodológica de la investigación”. En términos de la investigación empírica esto significa mantener desagregados los avances del modelo. Anteriormente, López Rabadán (2010) había revisado las últimas dos décadas de estudios sobre framing e identificó una perspectiva dominante donde "[...] la actividad mediática en sí misma se convierte en objeto y eje central de estos estudios” (p. 236). Ese podría ser apuntado como el lugar de encuentro entre el encuadramiento de la experiencia social planteada por Erving Goffman (1986), el encuadramiento de noticias de Mauro Porto (2004), así como las reflexiones sobre framing de Robert Entman (1993).

Justamente, el trabajo del investigador brasileño Mauro Porto contribuye a aclarar la relación entre framing y el pensamiento político -esfera dentro de la cual se ubica nuestro objeto de estudio- para él, "[...] los frames son elementos constitutivos importantes de narrativas y el proceso por el cual damos sentido al mundo de la política” (Porto, 1999, p. 14). De ahí la importancia de las palabras como unidades primarias en la construcción de las narrativas mediáticas y por consiguiente en la instauración de significados claves para la lectura de cualquier hecho social o periodísticamente relevante.

Los frames llaman la atención sobre algunos aspectos de la realidad mientras oscurecen otros elementos, lo que puede llevar a la audiencia a tener diferentes reacciones. Los políticos que buscan apoyo se ven obligados a competir entre sí y con los periodistas a través de los frames de noticias (Entman, 1993 p. 4).

A propósito, el desarrollo de los estudios sobre encuadramiento de noticias también ha llamado la atención de los académicos, Valera (2016, p. 26), por ejemplo, denuncia "el creciente divorcio de la investigación internacional sobre framing de sus primeras raíces sociológicas". Después de una revisión de literatura minuciosa, la investigadora asume el encuadramiento como "[...] un modelo de investigación capaz no sólo de determinar los encuadres periodísticos y sus efectos 
sobre el público, sino también de dar cuenta de la naturaleza construida y conflictiva del discurso público, situando el estudio de los mensajes periodísticos en el contexto de las múltiples disputas ideológicas que se producen en el espacio público" (Valera, 2016, p. 26).

De hecho, la autora propone superar el bies mediocéntrico, que hasta el momento ha definido las investigaciones sobre encuadramiento, mediante la recuperación de la base sociológica dentro de los estudios en comunicación. Lo cual significa dirigir el análisis de los frames mediáticos, considerando las particularidades e influencias del contexto social (Valera, 2016, p. 25). En sintonía con Recuero (2016), asumimos que la esfera pública constituida dentro de Twitter está atravesada por relaciones de poder que influyen en la difusión de ciertos mensajes en detrimento de otros. Estas relaciones también están vinculadas a las disputas del espacio fuera de línea. Algo que se ha podido observar mejor desde la perspectiva sociológica.

En 1999, Scheufele publicó un artículo en el que compiló veinticinco años de estudios sobre framing, distinguiendo cuatro procesos en torno a los cuales se desarrolló la investigación. El primero se refiere a la construcción de frames en comunicación con la ayuda de la influencia "externa". Un segundo proceso se centró en cómo estos frames de comunicación "se establecieron en los frames de pensamiento y el trabajo exacto en el proceso psicológico". El tercero mencionó la influencia de las "acciones ciudadanas" y los movimientos sociales sobre los periodistas durante el proceso de construcción de un frame. El cuarto proceso, por otro lado, se centra en el impacto a nivel individual, es decir, "en el pensamiento y los comportamientos o actitudes posteriores" (Chong \& Druckman, 2007, p. 51).

Más adelante, en 2005, luego de revisar la teoría y la tipología del framing de noticias, Claes H. De Vreese (2005) confirmó que “[...] una forma influyente para que los medios de comunicación moldean la opinión pública es encuadrar eventos y temas de manera específica” (p. 56). El investigador distingue dos tipos de enfoques en la hipótesis del framing. (1) inductivo, que "[...] se abstiene de analizar noticias con frames de noticias definidos a priori. Los frames emergen del material durante el curso del análisis"; y (2) el deductivo, que “[...] investiga qué componentes de los frames están definidos y operantes antes de la investigación. ¿Y qué elementos de una noticia constituyen un frame” (De Vreese, 2005, p. 56).

Desde un enfoque inductivo, el framing “debe ser comúnmente observado en la práctica periodística" (Cappella \& Jamieson, 1997, p. 72). Por otro lado, en una perspectiva deductiva, académicos señalaron la importancia de observar la presencia o ausencia de ciertas palabras clave (Entman, 1993) y de la elección del lenguaje, citas e información relevante (Shah et al. 2001). Como resultado, estos desarrollaron estudios sobre el framing que abordan diferentes niveles del proceso de construcción y establecimiento de frames como "paquetes interpretativos" (Gamson \& Modigliani, 1989). En concreto, es esta perspectiva la que sustenta el trabajo con palabras clave como unidades interpretativas básicas en discursos cortos al estilo de las plataformas de microblogging.

Al respecto, en el contexto de la comunicación digital y las plataformas de redes sociales, algunos ensayos se han propuesto comprender el funcionamiento del framing, que -a diferencia de los medios tradicionales- brindan la posibilidad de expresar ideas en tiempo real. En 2007, Zhou y Moy realizaron un estudio sobre los procesos de framing y la interacción entre la opinión pública en línea y la cobertura de los medios, en donde verificaron la relación entre la estructura de los medios -en un hecho sociopolítico en China- y la recepción de estos frames en la opinión pública en Twitter. Como 
referencia, utilizaron la investigación de Chong y Druckman (2007) sobre frames en entornos competitivos específicos; los autores sostienen que hay diferentes perspectivas sobre un tema desde el que se puede enmarcar el mismo tema. La cuestión, entonces, es evaluar cuál de estos "frames en competencia” será adoptado por la opinión pública (Chong \& Druckman, 2007). Los investigadores destacaron los elementos "cantidad" y "fuerza" para que uno u otro frame pudiera ser adoptado: el término "cantidad" se refiere a frames con muchas repeticiones, mientras que la variable "fuerza" se asocia con la credibilidad de la fuente (Druckman, 2001). En este sentido, el efecto de un frame podría estar determinado por una u otra característica.

No obstante, la investigación sobre encuadramiento en los entornos digitales enfrenta muchos de los tropiezos típicos de los estudios tradicionales, precisamente por la ausencia de un paradigma de investigación. Para D’Angelo (2002), llegar a establecer tal paradigma en la investigación sobre encuadramiento le permitiría a quienes lo estudian:

(a) compartir definiciones de conceptos centrales, (b) estar de acuerdo con el enunciado teórico más útil sobre la relación entre estos conceptos, (c) desarrollar hipótesis relevantes y preguntas de investigación y (d) acordar los métodos de investigación y la instrumentación con los que recopilar y analizar datos de la forma más adecuada (D’Angelo, 2002, pp. 871-872).

Atendiendo a las necesidades de este estudio, fue necesario tomar como punto de partida el trabajo de Chong y Druckman (2007), quienes demuestran que el efecto de framing ocurre cuando la comunicación aumenta el "peso" de una creencia nueva o existente en la formación de la actitud social general. En este sentido, es posible que un tema determinado que reciba una amplia cobertura sea más accesible en la mente del individuo y tenga un mayor efecto en su opinión (Chong \& Druckman, 2007).

Para el caso analizado en este artículo, tenemos dos posturas: por un lado, la del entonces Ministro de Educación de Brasil, Abraham Weintraub, quien -en un anuncio en el año 2019-informó sobre el recorte de fondos a las universidades federales que "no tuvieron un desempeño satisfactorio y promovieron el desorden en sus campus" (sic)4. Este hecho detonó declaraciones y manifestaciones en contra del gobierno en todo Brasil. Por otro lado, estudiantes, docentes, funcionarios de universidades federales y defensores de la educación reaccionaron ante la medida, que llamó la atención porque correspondía a una reducción de más de la mitad del presupuesto impuesto a otras instituciones educativas públicas. Luego, esta reducción se extendió a todas las universidades federales del país, inicialmente anunciada como el $30 \%$ del presupuesto total y luego como el $30 \%$ del presupuesto llamado discrecional (es decir, gasto no obligatorio), correspondiente a aproximadamente $\mathrm{R} \$ 1.5$ mil millones. Las universidades rechazaron la medida y defendieron la importancia de la investigación científica y la educación pública gratuita. Con base en lo anterior, formulamos:

4 "Las universidades que, en lugar de buscar mejorar el rendimiento académico, están haciendo un desastre, tendrán fondos reducidos”, dijo el ministro. "La universidad debe tener suficiente dinero para hacer un desastre y un evento ridículo". Dio ejemplos de lo que considera un desastre: "Sem-terra en el campus, gente desnuda en el campus". Primero, tres universidades ya han cumplido estos criterios y han reducido las transferencias: la Universidad de Brasilia (UnB), la Universidad Federal Fluminense (UFF) y la Universidad Federal de Bahía (UFBA). Recuperado el 26 de agosto de 2019, de https:// educacao.estadao.com.br/noticias/geral,mec-cortara-verba-de-universidade-por-balburdia-e-ja-mira-unb-uff-e- Ufba, 70002809579 
Hipótesis 1: Las palabras clave de Estadão.com y Folha Online muestran un discurso homogéneo durante el período de análisis, lo que contribuye a la aceptación de sus frames por parte de la audiencia.

En el estudio del Foro Qiangguo en China, Zhou y Moy (2007) organizaron el método en tres fases para probar la relación entre la frecuencia y la aceptación de un frame, correlacionando la cobertura de los medios y la opinión en línea con las funciones sugeridas por Entman (1993):

Después de una revisión completa del asunto, se pidió a los entrevistados que escogieran cuál de las cuatro funciones de los frames de Entman: (F1) definición del problema; (F2) interpretación causal; (F3) evaluación moral y (F4) recomendación de tratamiento: era la función principal y también determinaba qué estructura específica se usaba para cumplir esta función. (Zhou \& Moy, 2007, p. 86).

La investigación desarrollada por Zhou y Moy (2007) profundizó en la comprensión de la construcción y el establecimiento de frames en entornos digitales, específicamente en las plataformas de redes sociales. A propósito, el informe del Latinobarómetro ${ }^{5}$ (2018) -una organización sin fines de lucro que realiza encuestas periódicas de opinión pública en América Latina- corrobora la idea de que las plataformas de redes sociales facilitan que los ciudadanos ejerzan su libertad de expresión con toda amplitud. En el documento mencionado, Twitter ocupa el tercer lugar entre las redes sociales más utilizadas en temas que afectan la democracia entre el público latinoamericano. Para los estudios sobre framing, esto representa un campo fértil en donde explorar las eficiencias de los encuadres en un ambiente donde, además de ser apto para el debate político, concurren no sólo frames de noticias.

El estudio también abordó el tema basándose en un proceso de interacción a partir del cual se construyen conjuntos de frames que refuerzan la forma de interpretar y dar relevancia a un cierto aspecto de las noticias. Dado que los brasileños se hallan entre quienes hacen un mayor uso de las redes sociales en el mundo (Newman et al., 2019), es relevante resaltar que la acción del presidente Jair Bolsonaro en tales plataformas tiene una fuerte influencia en la opinión pública. Dada en particular por el contexto de polarización política desatada en Brasil después de la destitución de la ex presidenta Dilma Rousseff en 2016, y la elección del actual presidente. De manera que el recorte de fondos en las universidades federales realizado en 2019 no pasaría desapercibido para la opinión pública ni para la prensa. Así, considerando tanto el aporte de los autores, como el contexto político en Brasil, presentamos la segunda hipótesis:

Hipótesis 2: Debido al escenario de polarización de Brasil, el público en línea adoptará más fácilmente en sus publicaciones de Twitter las palabras clave relacionadas con las funciones de interpretación causal (F2) y evaluación moral (F3) presentadas por los medios.

A continuación, presentamos la metodología utilizada para la recopilación e interpretación de datos de la investigación, así como los resultados obtenidos.

5 Fuente: http://www.latinobarometro.org/lat.jsp. Acceso: 24 de agosto. 2019. 


\section{Metodología}

La investigación se configuró con un enfoque exploratorio y cuantitativo-cualitativo ${ }^{6}$. Para alcanzar la complejidad del objeto de estudio y comprender la dinámica sociocultural que traspasa esta investigación, proponemos una mirada multidimensional que utiliza la estrategia de triangulación metodológica como una posibilidad para construir coherencia y cohesión. Denzin y Lincoln (2006) aclaran que “[...] el uso de múltiples métodos, o triangulación, refleja un intento de asegurar una comprensión profunda del fenómeno en cuestión” (p. 19).

Así, la investigación se llevó a cabo en tres etapas. La primera correspondió a una revisión de la literatura: identificamos investigaciones previas que abordaron Twitter como un espacio de trabajo y que podrían guiarnos a comprender el papel del framing en esta red social. La segunda fase incluyó una revisión de los artículos publicados por Folha Online y Estadão.com durante el tiempo determinado para este estudio, para luego llevar a cabo un análisis de contenido. Por fin, realizamos una investigación empírica, cuyo objetivo era probar nuestras hipótesis basadas en la relación entre los frames de los medios y la opinión de los lectores en Twitter sobre el tema, a partir de las palabras clave.

El recorte fue el manejo que la prensa dio al hecho sobre el recorte de fondos en la educación superior en Brasil. El objetivo fue poner a prueba nuestras hipótesis basadas en la relación entre los marcos de los medios y la opinión de los lectores en Twitter sobre el tema en función de las palabras clave.

Defendemos la elección del corpus formado por los tuits de los periódicos Folha de São Paulo y Estadão de São Paulo, ya que son dos periódicos de gran audiencia y credibilidad nacional, con líneas editoriales diferentes. Acogemos la definición de una línea editorial de José Marques de Melo, uno de los autores seminales en el campo de la investigación periodística en Brasil, quien afirma:

[...] la selección significa, por lo tanto, la perspectiva a través de la cual la empresa de periódicos ve el mundo. Esta visión parte de lo que se decide publicar en cada edición, privilegiando ciertos temas, resaltando ciertos personajes, oscureciendo algunos y omitiendo varios (Marques De Melo, 2003, p. 75).

Históricamente, Folha y Estadão no solo han mantenido un liderazgo entre los medios más consultados en Brasil, sino que han representado posturas disímiles frente a las realidades políticas y sociales, como veremos más adelante. Temas controvertidos como la despenalización del aborto, la legalización de la marihuana y la pena de muerte, por ejemplo, son abordados por Folha de S. Paulo para encajar en una visión más liberal de la sociedad. A su vez, O Estadão de S. Paulo expresa enfoques más conservadores sobre los mismos temas.

A parte de que las posturas de estos dos medios son opuestas, el hecho de que ambos cuenten con manuales de redacción en el que indican el periodismo que pretenden ejercer y que son referencia en los cursos de pregrado en periodismo de las universidades brasileñas fue otro criterio de selección. En estos, cada medio se presenta como pluralista, independiente y no partidista. Sin embargo, esta proclamada neutralidad no siempre se verifica como demuestran Agostinho y Lannes (2008). Pues según escriben los autores de Folha de São Paulo:

6 Nos asociamos a Oliveira (2011, p. 27), para quien “[...] parece haber un consenso, por lo tanto, en cuanto a la idea de que los enfoques cualitativos y cuantitativos deben verse como complementarios, en lugar de competir mutuamente”. 
[...] este manual general no sustituye a un curso de periodismo y mucho menos a la experiencia práctica de la escritura [...]. Su objetivo es únicamente traducir, en reglas empíricas y sencillas, el concepto de periódico que se busca practicar en Folha. (Manual Folha, 1984).

Por su parte, el Manual de Redação de O Estado de São Paulo, lanzado en 1990, enumera, además de los comportamientos que debe adoptar el periodista al redactar un texto, la necesidad de evitar palabras o expresiones que puedan generar dudas o ser interpretadas como ambigüedad por el lector (Manual Oesp, 1990).

De la misma forma, entendemos que las versiones en línea son más adecuadas para probar nuestras hipótesis ya que mantienen los supuestos antes mencionados y además reportaron un aumento del $33 \%$ en las suscripciones digitales de aquellos medios que tienen ediciones web en comparación con 2018 (Newman et al., 2019). Por lo tanto, el análisis de contenido es apropiado en el contexto de la investigación sobre framing, ya que "[...] el método presupone una lectura crítica del significado de los mensajes, su contenido manifiesto o velado, es decir, lo que se dice y lo que está implícito o incluso disfrazado" (Bonone, 2017, p. 84). A partir del análisis de contenido, definimos las unidades de análisis y las categorías en las que se dividieron.

En cuanto a la investigación empírica, esta se llevó a cabo en tres etapas. Primero, delimitamos el tema y la periodicidad, para luego recopilar los artículos en los sitios web Folha Online y Estadão.com. A continuación, utilizamos la herramienta TweetDeck ${ }^{7}$ para buscar las publicaciones de estas historias en las cuentas de Twitter de ambos medios. Hicimos lo mismo con los tuits de la audiencia, y consideramos tanto el tema como la periodicidad. En ello, contabilizamos, identificamos, seleccionamos y parametrizamos los post, para establecer categorías de palabras clave de acuerdo con las cuatro funciones de los frames enumeradas por Entman (1993): definición del problema, interpretación casual, evaluación moral y recomendación de tratamiento. Finalmente, tabulamos los datos del número de repeticiones para probar las hipótesis.

\subsection{Delimitación del tema y recopilación de artículos}

En la primera recopilación, utilizamos el motor de búsqueda de cada medio para filtrar y seleccionar los artículos que trataban sobre el recorte de fondos en las universidades federales. Las palabras clave utilizadas fueron: corte de verbas; universidade federal; universidade; corte; UFs; bloqueio; Abraham Weintraub; orçamento; balbúrdia; ministro; educação; MEC; y Ministério da Educação. Sumando los dos medios, encontramos 214 artículos publicados entre el 30 de abril y el 30 de junio de 2019. La primera fecha fue definida por el anuncio de la medida provisional sobre el recorte de fondos de las universidades federales. Sobre la fecha final, y de acuerdo con las recomendaciones del estudio de Recuero y Zago (2009), cuanto más visible sea un emisor particular del tuit, mayor será la recirculación del mismo tema. Por esta razón, incluso con el número de personas que alcanzan las publicaciones de Folha y Estadão en sus cuentas de Twitter (5,7 millones y 6, 9 millones de seguidores, respectivamente), fue necesario considerar tanto el nivel de engagement, como la multiplicidad de contenidos a los que los usuarios están expuestos en dicha red social. Luego, el tiempo para obtener resultados efectivos no podía ser menor a dos meses. La compilación incluyó solo artículos informativos, informes especiales y notas. En

$7 \quad$ TweetDeck es un software que permite publicar, monitorear y administrar perfiles en Twitter. 
esta, excluimos artículos de opinión, cartas de lectores y columnas. Por lo tanto, agregando el material de los sitios web de ambos periódicos, obtuvimos 154 artículos para examinar.

A continuación, utilizamos las mismas palabras clave en el motor de búsqueda TweetDeck para encontrar las publicaciones asociadas a estos artículos. Obtuvimos 78 posts para Folha Online y 80 posts para Estadão.com, sumando 158 publicaciones relacionadas con el recorte de fondos en universidades federales en el período mencionado. Como una manera de verificar específicamente las publicaciones en Twitter, consideramos tanto el contenido de cada tuit como el lead del artículo. Aquí excluimos el título, ya que, a menudo, coincide con el contenido de la publicación y no proporciona información adicional.

\subsection{Selección y parametrización de los resultados}

A partir de los 158 post encontrados en Twitter correspondientes a los 154 artículos previamente referidos y filtrados en los sitios web de ambos medios, identificamos las palabras más utilizadas tanto en los leads de las noticias, como en el texto del post en Twitter, a través del software Online Word Counter. ${ }^{8}$ Enumeramos 345 palabras que tenían al menos dos repeticiones. Seleccionamos las primeras 110 palabras con más repeticiones (excluyendo artículos y conectores) y trabajamos solo con aquellas que hacía referencia al debate y, por eso, eran susceptibles a tener poder de encuadramiento ${ }^{9}$ (Entman, 1993). Después de esta depuración, consideramos 70 palabras en Folha Online y 93 palabras en Estadão.com.

Nuevamente, utilizamos la herramienta TweetDeck, con los mismos filtros empleados en la identificación de los artículos, para encontrar los tuits de las audiencias de esos medios. Distinguimos tres categorías de tuits: a) respuestas a los post de los artículos publicados por los periódicos; b) tuits que mencionaban o etiquetaban a los periódicos o c) tuits en los cuales el enlace del artículo fue directamente compartido del sitio web.

A continuación de la recolección de datos, para verificar los post de las audiencias de cada medio, realizamos un procedimiento idéntico al examinar los artículos de Folha Online y de Estadão.com. Iniciamos con un conteo de palabras, seleccionamos las 110 con más repeticiones y excluimos los artículos y conectores. Las palabras recolectadas fueron $78 \mathrm{en}$ los tuits del público de la Folha Online y 96 en los tuits del público de Estadão.com. En una primera proyección, hicimos una distribución de probabilidades al comparar el uso de palabras según cada fuente o autor (periódicos y audiencias de cada medio) explicadas en las Figuras 1 y 2. Utilizamos por lo menos una palabra clave para definir cada función.

8 Recuperado el 24 de agosto 2019 de http://www.contadordepalavras.com/

9 “Los frames ejercen su poder a través de la descripción selectiva u omisión de características de una situación” (Entman, 1993, p. 56). 
Figura 1. Grupo de palabras clave publicadas en la Folha Online y en los tuits de sus lectores

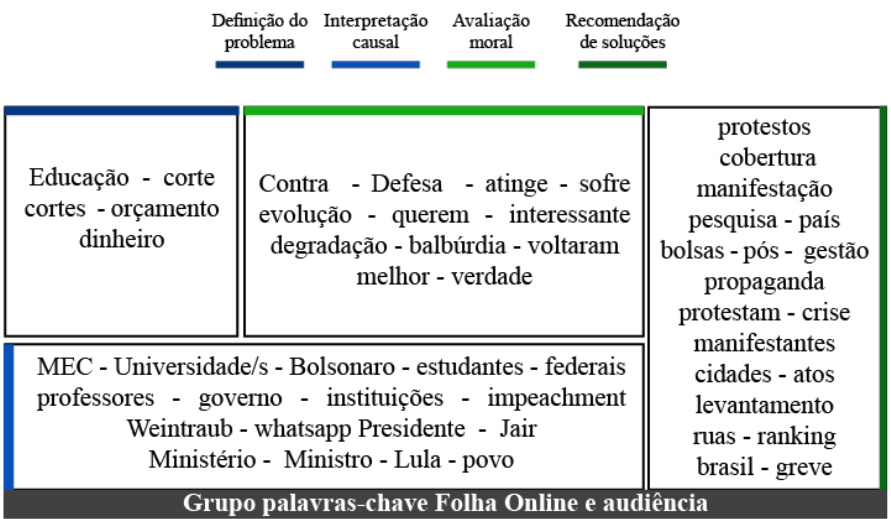

Fuente: elaboración de las autoras (2019)

Figura 2. Grupo de palabras clave publicadas en Estadão.com y en los tuits de sus lectores

\begin{tabular}{|c|c|c|}
\hline $\begin{array}{c}\text { Educação - corte } \\
\text { cortes - bloqueios } \\
\text { verbas - orçamento } \\
\text { verba - suspensão } \\
\text { dinheiro - recursos } \\
\text { cortará - redução } \\
\text { medida }\end{array}$ & $\begin{array}{c}\text { Contra - não - defende - defesa - propaganda - atinge } \\
\text { atingir - suspensão - sofra - evolução - custeio - querem } \\
\text { interessante - degradação - balbúrdia - melhor - úteis } \\
\text { levantamento - promovidos - verdade - boato - idiotas } \\
\text { oposição - confronto - contingenciamento - bagunça } \\
\text { ridículo - inspiração }\end{array}$ \\
\hline \multicolumn{2}{|c|}{$\begin{array}{c}\text { MEC - Bolsonaro - universidade/s - estudantes - país } \\
\text { federais - professores - alunos - ministro - pesquisa } \\
\text { governo - instituições - repasses - Weintraub } \\
\text { Presidente - Jair - Ministério - Brasil - Lula }\end{array}$} & $\begin{array}{l}\text { protesto/s - cobertura } \\
\text { manifestação - bolsas } \\
\text { povo - político } \\
\text { gestão - protestam } \\
\text { atos - levantamento } \\
\text { ruas - paralisação } \\
\text { juíza - congresso }\end{array}$ \\
\hline \multicolumn{2}{|c|}{ Grupo palavras-chave Estadão.com e audiência }
\end{tabular}

Fuente: elaboración de las autoras (2019)

\subsection{Categorización de palabras clave según las funciones del framing}

Después de identificar una distribución semejante entre los destaques realizados en los artículos de Estadão.com y la opinión de sus lectores en los tuits, buscamos comprender relaciones más específicas. Por consiguiente, categorizamos las palabras de cada periódico y las de sus audiencias en cuatro grupos. El criterio fue la correspondencia con alguna de las cuatro funciones de los frames; en esa clasificación se incluyó tanto el número de repeticiones de cada término, como 
el aporte que suponía al debate cada término. En otras palabras, qué aspecto del asunto en cuestión estaba abordando o definiendo un actor en particular. Contamos el total de repeticiones en los grupos (de acuerdo con la función) y obtuvimos los porcentajes con relación al total de la muestra. A partir de ese número porcentual, verificamos la correspondencia obtenida entre cada autor del post (medio y audiencia) y la variable nominal determinada, en este caso, las funciones del frame. Posteriormente, cruzamos los porcentajes de uso de las palabras clave entre: (a) los dos periódicos; (b) entre los dos periódicos y sus respectivas audiencias y (c) entre los públicos de ambos periódicos. Tabulamos los datos en gráficos de línea para identificar los puntos de encuentro significativos en los resultados obtenidos (ver resultados).

Distinguiendo el autor del post y la utilización de palabras que pudieran implicar la definición de problema, interpretación causal, evaluación moral y recomendación de tratamiento (Entman, 1993), buscamos comprobar nuestras hipótesis. Estas parten del supuesto que, en una situación política polarizada, las funciones del framing que aparecen en los discursos mediáticos son también acentuadas en la opinión del público en Twitter de dichos medios. Después de una recopilación de resultados, y de la presentación del corpus y del proceso metodológico que resultó en la selección de este contenido, pasamos a la depuración del análisis de contenido.

\subsubsection{Análisis de contenido}

Utilizamos elementos del modelo metodológico establecido por Zhou y Moy (2007) para evaluar el efecto del framing de los medios en los comentarios de Twitter. Las unidades de análisis en los estudios sobre framing son variadas; esto puede incluir una palabra, una metáfora, un ejemplar, un eslogan, una representación o una imagen (Gamson, \& Modigliani, 1989); un párrafo (Akhavan-Majid, \& Ramaprasad, 2000); o un artículo de prensa (Callaghan, \& Schnell, 2001; Yang, 2003). Aquí, las unidades de análisis fueron las palabras clave. Consideramos, para cada medio, las palabras que envuelven alguna de las cuatro funciones de framing establecidas por Entman (1993), según el razonamiento que explicamos a continuación.

\subsubsection{Definición del problema}

Para definir la naturaleza del problema relacionado con el evento descrito, las audiencias y los medios emplearon una de las dos perspectivas suscitadas: en la primera, era enfatizado el recorte de recursos como un factor que impacta la educación brasileña en su totalidad, reiterando la necesidad de educación pública, gratuita y de calidad. En segundo lugar, la actividad de las universidades federales era investigada y cuestionada; en este punto se destaca la balbúrdia ${ }^{10}$ y la supuesta falta de compromiso de los estudiantes de dichas instituciones (atribuyendo la necesidad de que el gobierno actúe ante la situación). Siendo así, consideramos palabras que se articulaban con alguna de las dos posturas mencionadas y que respondían a la pregunta: ¿Qué está sucediendo? Es decir, buscamos “[...] determinar lo que un agente causal está haciendo, con cuáles costos y beneficios; generalmente medidos en términos de valores culturales comunes” (Entman, 1993, p. 52).

10 En portugués la palabra balbúrdia hace referencia a desorden, falta de productividad o aprovechamiento de los recursos públicos. Término con el cual el ministro de educación se refirió a la actividad dentro de las universidades federales. 


\subsubsection{Interpretación causal}

Los tuits y las noticias también mostraron una tendencia a atribuir el hecho a varios factores. La estructura de los medios sugirió tres factores causales principales: el gobierno desconoce los problemas educativos del país, la desigualdad social privilegia a los ricos y no a los pobres, y la "balbúrdia" y la falta de compromiso por parte de las universidades federales motivan el recorte. En esta función, incluimos aquellas palabras que mencionaron actores o elementos causales: - ¿Qué / quién está causando el problema? Es decir, el esfuerzo fue “identificar las fuerzas que crean el problema” (Entman, 1993, p. 52).

\subsubsection{Evaluación moral}

Dado el carácter político de la situación, las evaluaciones morales sobre el hecho y los actores expresados en las publicaciones en Twitter recordaron la necesidad de una educación pública de calidad, al tiempo que discutieron la falta de compromiso de los estudiantes con la enseñanza. Asimismo, enfatizaron el papel de los medios y la opinión pública en la "supervisión" del ministro de educación y en la evaluación de la gestión del gobierno actual con respecto a la educación. Incluimos en esta función palabras que responden a la siguiente pregunta: — ¿Cómo calificar la situación? O, en otras palabras, qué términos se usaron para "juzgar los agentes causales y sus efectos” (Entman, 1993, p. 52).

\subsubsection{Recomendación de soluciones}

La mayoría de los frames sugirieron soluciones para una educación pública de calidad y enfatizaron en la necesidad de una reforma educativa o incluso animaron a realizar cambios en la estructura del gobierno. Otros, exigieron acciones civiles en apoyo de algunas de las corrientes frente a la situación. En esta función, tuvimos en cuenta aquellas palabras que respondieron las preguntas: — ¿Qué se puede hacer? ¿Qué efecto e impacto tendrá la medida? Es decir, aquellos que buscaron “ofrecer y justificar tratamientos para el problema y predecir sus posibles efectos” (Entman, 1993, p. 52).

\subsection{Variables cuantitativas}

Además de las variables nominales, el estudio consideró como variable cuantitativa la reiteración que la prensa dio a sus artículos sobre el tema. La medición se hizo efectiva mediante la frecuencia (\%) de cada frame ${ }^{11}$ congruente con la existencia de palabras clave en los artículos de Folha Onliney Estadão.com y en las respuestas de los usuarios en los tuits. Con esta y las otras variables, realizamos cuatro correlaciones. El objetivo era examinar si la opinión de los usuarios de Twitter sobre el tema está asociada no solo con un tipo de función de frame, sino también con la intensidad del uso de palabras en esta categoría en la cobertura de los medios. Profundizamos esta discusión en los resultados.

11 En este punto del estudio, llamamos a los frames las palabras clave que se asignaron a la función de encuadre sugerida por Entman. 


\section{Resultados}

Buscamos identificar tanto las similitudes y las diferencias en los discursos sobre el recorte de fondos en la educación superior en los periódicos Folha Online y Estadão.com, así como la aceptación de los frames propuestos por los medios de comunicación en la opinión de los usuarios en sus tuits. Teniendo en cuenta que el espacio de escritura en Twitter es de solo 280 caracteres -además de la velocidad de actualización de la plataforma-, concentramos el análisis en palabras clave como punto de partida del análisis para la comprensión de estos frames en la red social.

Una primera prueba experimental nos mostró una distribución de probabilidad de las palabras más utilizadas en cada vehículo, durante los dos meses de recopilación de datos, con relación a su audiencia. Hubo algunos puntos en común en las palabras descriptivas sobre el problema en los dos periódicos, aunque distantes en la proporción de uso, como se muestra en los Gráficos 1 y 2.

Gráfico 1. Distribución de probabilidad de palabras clave entre Folha Online (azul claro) y su audiencia (azul oscuro)

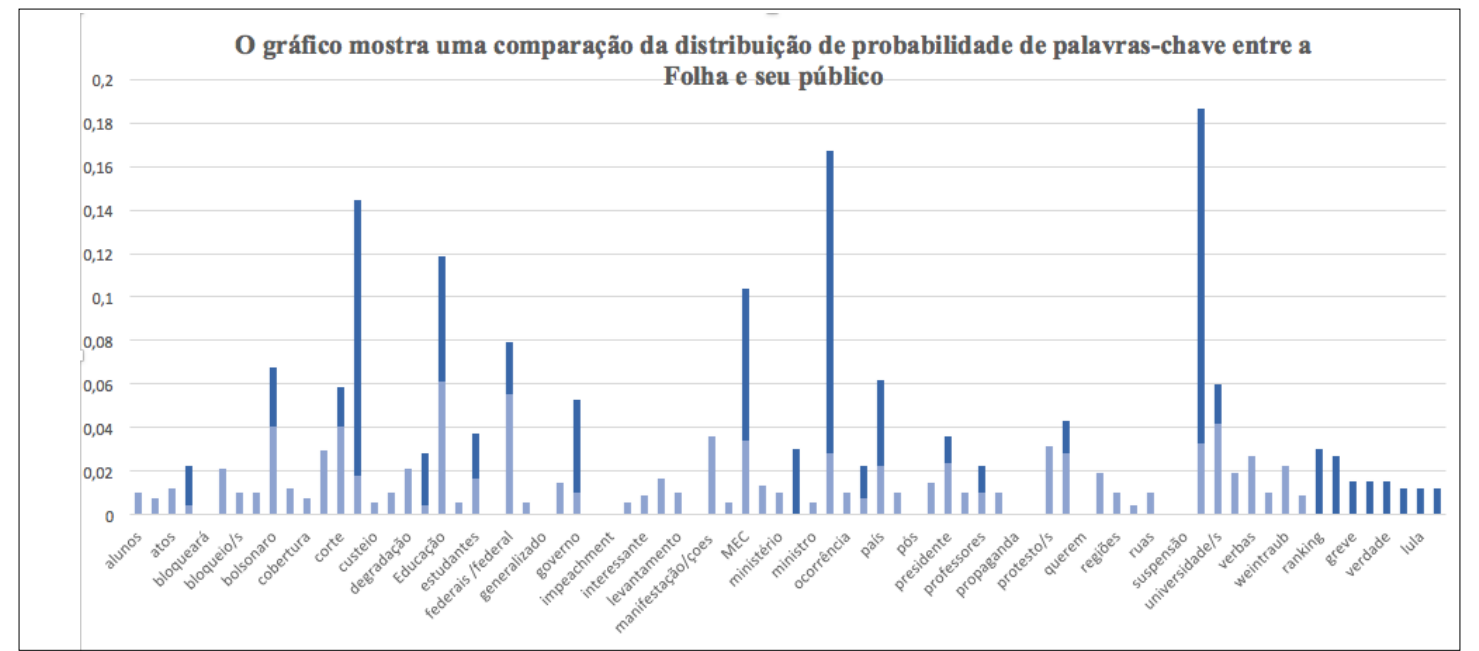

Fuente: elaboración de las autoras (2019) 
Gráfico 2. Distribución de probabilidad de palabras clave entre Estadão.com (azul claro) y su audiencia (azul oscuro)

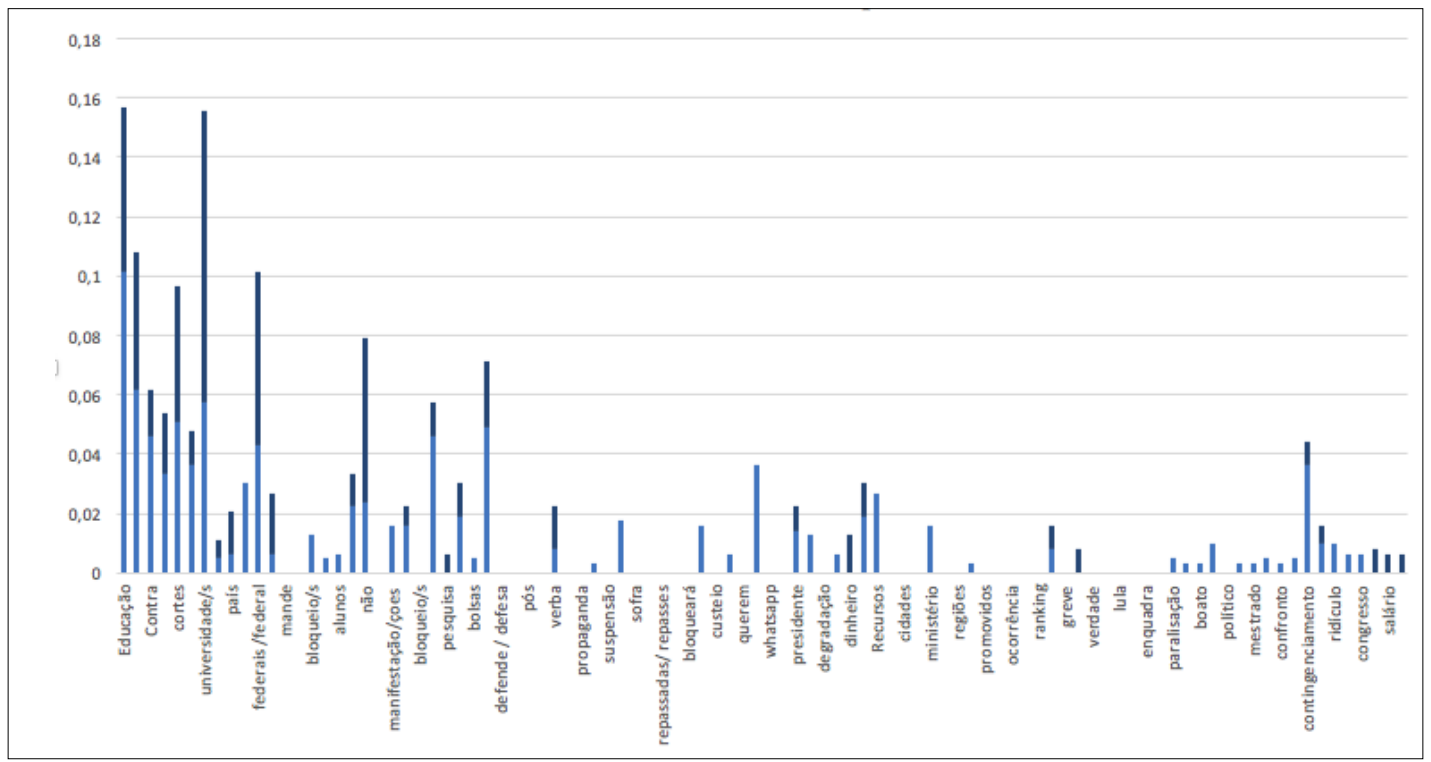

Fuente: elaboración de las autoras (2019)

Basándonos en lo anterior, nuestra primera hipótesis afirmaba que habría una aproximación entre los discursos de Folha Online y Estadão.com y que esto favorecería la aceptación de los frames en la opinión de sus audiencias (H1). Después de señalar las palabras en cada función del frame, cruzamos los porcentajes de uso de cada grupo de palabras en los respectivos medios. Ambos siguieron una línea similar (con respecto al porcentaje de uso) solo en la segunda y tercera función de los frames (interpretación causal y evaluación moral). En esta evaluación, Folha Online tuvo 48.29 \% y Estadão. com, $43.51 \%$ de las palabras que evocaron los agentes causales del problema. Con respecto a la evaluación moral, ambos usaron palabras similares que juzgaron los recortes en los fondos o cualquiera de las partes involucradas en el proceso: 11.74 \% en Folha Online y 18.06 \% en Estadão.com.

En las otras dos funciones de los frames (definición del problema y recomendación de tratamiento), observamos que las palabras correspondientes a estas se usaron en una proporción diferente en cada periódico, con un porcentaje de $16.66 \%$ en Folha Online para definir el problema y 30.70 \% para Estadão.com en el mismo rol. En cuanto a la recomendación de tratamiento, Folha Online utilizó el 23.29 \% de las palabras que se referían a cuestiones de tratamiento de los problemas y las posibles consecuencias en comparación con Estadão.com, que utilizó solo el 7.71 \% (ver Gráfico 3).

En consecuencia, la primera hipótesis (H1), que anticipa una línea porcentual más o menos homogénea, está parcialmente confirmada, ya que los puntos de similitud en los discursos de ambos solo se acercan en dos de las cuatro funciones de los frames utilizados como categorías nominales. Esto también nos muestra que Estadão.com utilizó más palabras 
que intentaron definir o asunto como educação, cortes, suspensão, dinheiro, relacionado con artículos sobre la medida per se y sobre lo anunciado por el gobierno. Por otro lado, Folha Online atribuyó un peso adicional a los artículos que se referían a las acciones de los estudiantes y el gobierno después del anuncio de la medida, al incluir palabras como greve, protestos, manifestação y bolsa.

En este punto, vale la pena mencionar la relación de estos resultados con las líneas editoriales de cada uno de los medios analizados. La socióloga Gisela Taschner explica que el actual Grupo Folha fue creado en oposición al principal periódico de la ciudad, O Estado de São Paulo, representante de las élites rurales, más conservadoras, tradicionales y rígidas (Almeida, 1993). En el sitio web del Grupo, la línea editorial se describe como “[...] la búsqueda de periodismo crítico, no partidista y pluralista. Estas características, que guían el trabajo de los profesionales del Grupo Folha, se detallan desde 1981 en diferentes proyectos editoriales"12.

Taschner aclara que la aparición del periódico O Estado de São Paulo -hoy Grupo Estado, del cual hace parte Estadão. com- está vinculada a una lucha política, es decir, ya tenía una línea editorial predefinida: “[...] la organización empresarial era un marco material para lograr el objetivo político” (Taschner, 1992, apud Almeida, 1993, p. 30). En la evaluación del autor, Estadão mantuvo su postura tradicional al unir el conservadurismo político y el liberalismo económico en sus editoriales. Notas e informações es una de las columnas más emblemáticas del medio hasta la fecha. Sin embargo, desde el golpe militar de 1964, y especialmente después de 1968, el periódico ha tomado posiciones más liberales también en la esfera social y política" (Almeida, 1993, p. 32).

Gráfico 3. Comparación de porcentajes de uso de palabras clave en cada función del frame entre Folha Online y Estadão.com

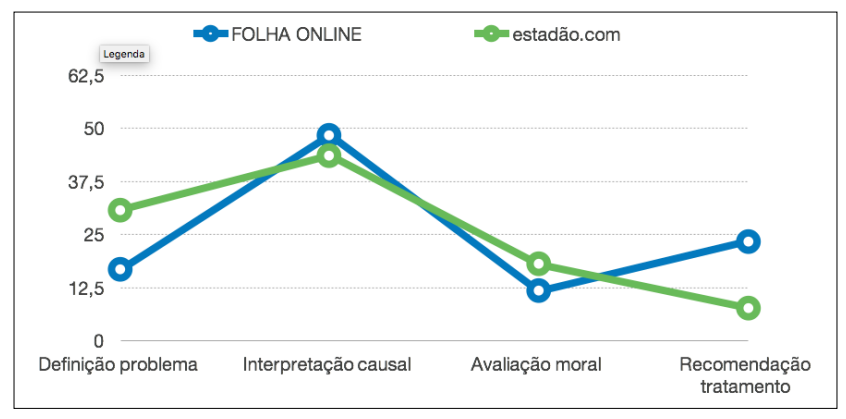

Fuente: elaboración de las autoras (2019)

Para probar las relaciones de los discursos mediáticos con los de sus audiencias y determinar la aceptación de los frames -considerando el entorno de polarización política en Brasil-, nuestra segunda hipótesis predice que la audiencia en Twitter probablemente aceptaría más palabras relacionadas con las funciones de interpretación causal (F2) y evaluaciones morales (F3) presentadas por los medios, en las que Estadão.com y Folha Online tuvieron porcentajes de uso similares.

12 Recuperado en 24 agosto, 2019 de https://wwwl.folha.uol.com.br/institucional/ 
Así también, anticipamos que el público usaría estas palabras en sus publicaciones en Twitter en una proporción similar, para representar sus posiciones en una situación en la que al menos el 95 \% de la muestra recolectada tenía una opinión sobre la medida, como se muestra en el Gráfico 4.

Gráfico 4. Tendencia en los comentarios: en contra, a favor, neutral o ambivalente frente al hecho del recorte de fondos en universidades federales

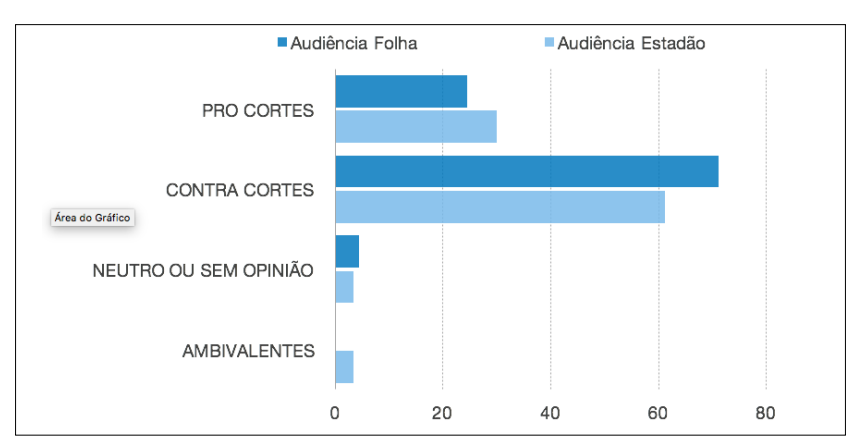

Fuente: elaboración de las autoras (2019)

El cruce de porcentajes entre los usos de cada medio y sus audiencias, obtenidos en cada una de las categorías nominales (funciones de los frames), se muestran en los Gráficos 5 y 6. En la Folha Online (Gráfico 5), el comportamiento fue similar. No obstante, la medición del uso muestra solo una correspondencia significativa en aquellas palabras que pertenecen a la interpretación causal: el medio las usó el 48.29 \% de las veces y su audiencia, el 51.24 \%. Las palabras correspondientes a las evaluaciones morales apuntaban una distancia de más de 5 puntos porcentuales entre los usos de Folha Online (11.74 \%) y los de su público (5.69 \%). Además, las distancias en las otras categorías no mostraron una relación cercana entre las palabras utilizadas por el periódico (F1: 16.66 \%; F4: 23.29 \%) y por su audiencia (F1: 28.46 \%; F4: 14.59 \%).

Gráfico 5. Comparación de porcentajes en el uso de palabras clave entre Folha Online y su audiencia

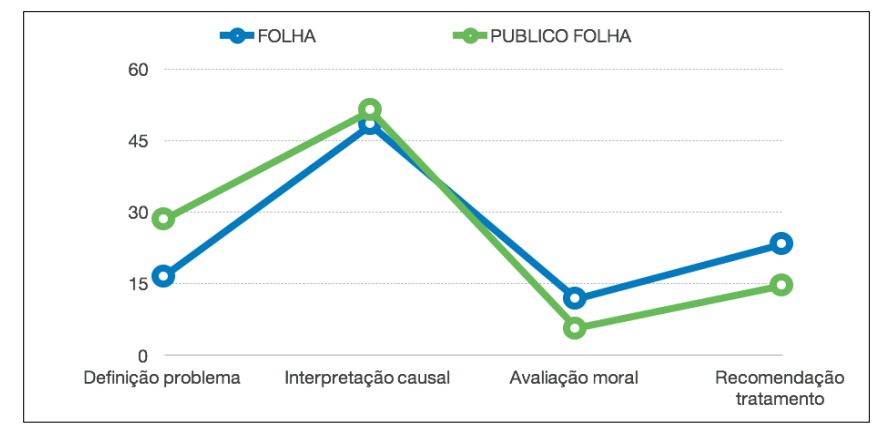

Fuente: elaboración de las autoras (2019) 
Se realizó el mismo procedimiento para examinar Estadão.com (Gráfico 6). Hubo puntos de encuentro en dos de las cuatro categorías nominales. Al definir el problema, el periódico utilizó un porcentaje de 30,70 \% de las palabras correspondientes a esta función. En las respuestas de su audiencia, este grupo de palabras se usó en un $30.25 \%$.

En las categorías mencionadas en nuestra segunda hipótesis, se encontró una relación relevante entre el uso de palabras del medio y su audiencia en la variable evaluación moral. Las palabras categorizadas en la función de evaluación moral se encontraron en un porcentaje de $18.06 \%$ en el periódico y $18.48 \%$ en su audiencia. Por su lado, las interpretaciones causales indican un porcentaje de 43.51 \% en Estadão.com y 51.26 \% en su audiencia. Por lo tanto, nuestra segunda hipótesis fue apoyada en el frame de interpretación causal (F2) sólo en Folha Online y en el frame de evaluación moral (F3) únicamente en Estadão.com.

Gráfico 6. Comparación de porcentajes de uso de palabras clave entre Estadão.com y su audiencia

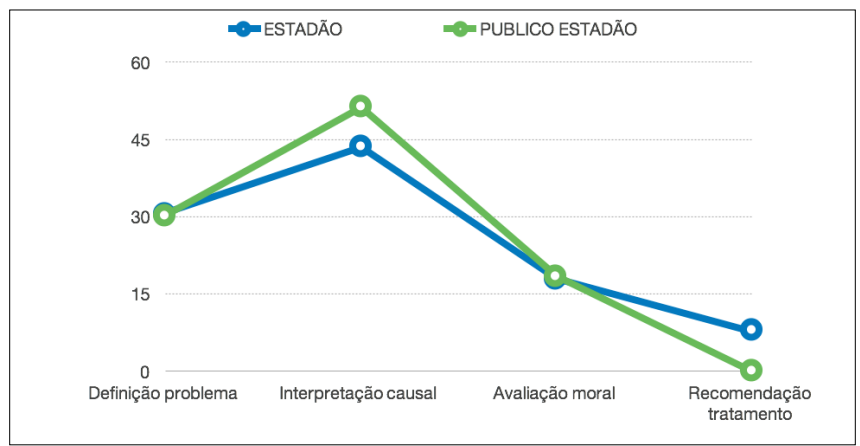

Fuente: elaboración de las autoras (2019)

Para tener una perspectiva adicional sobre la relación entre el uso de las palabras clave identificadas en cada una de las audiencias de los medios, comparamos los porcentajes de uso entre las dos audiencias en relación con cada categoría nominal, cuyos resultados se pueden ver en el Gráfico 7. Encontramos aproximaciones significativas solo en las dos primeras funciones de los frames que se referían al uso de palabras clave en la definición del problema, que en la audiencia de la Folha era del 28.46 \% y en la audiencia de Estadão.com, del $30.25 \%$. 
Gráfico 7. Comparación de porcentajes de uso de palabras clave entre los públicos de Estadão.com y Folha Online

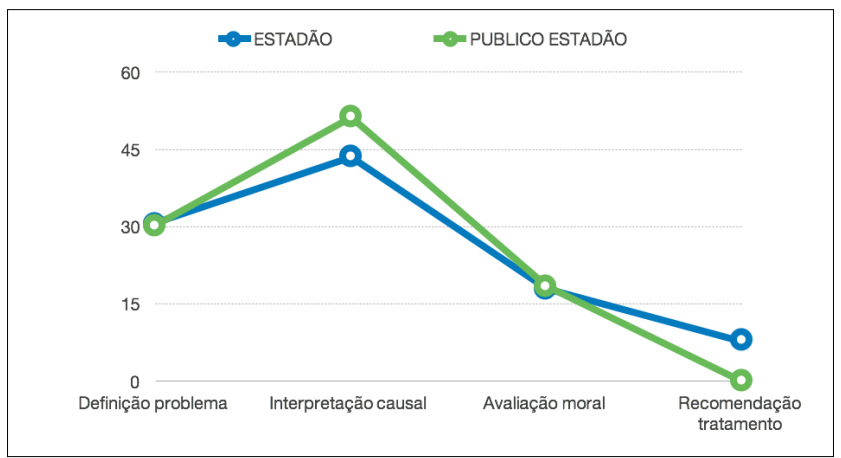

Fuente: elaboración de las autoras (2019)

Las palabras que mencionaron o "identificaron las fuerzas que crearon el problema" (Entman, 1993, p. 53), y correspondían a la segunda función de los frames, fueron utilizadas por el público de Folha Online en un porcentaje del 51,24\% y por el público de Estadão.com en un 51.26 \%. La correspondencia casi exacta está relacionada con el hecho de que las audiencias producen discursos más coherentes entre sí cuando definen la situación e identificar agentes causales en ella, y no en evaluaciones morales ni en las formas de abordar el problema o sus posibles consecuencias.

Esto es comprensible en una situación política polarizada en la que la adopción de frames que sugieran cambios en las evaluaciones y actitudes depende del nivel de engagement con el hecho. Por lo tanto, y volviendo al Gráfico 3, el porcentaje de la audiencia que podría considerarse sin o con poco interés y compromiso con la situación no alcanza el 5\%. En resumen, la mayoría de las personas de nuestra muestra tenía, en sus comentarios, algún tipo de posición con respecto a la medida, lo que corrobora la declaración de Entman (1993, p. 55) de que “[...] el poder de las noticias puede ser auto reforzador". Es posible inferir que las personas encontraron argumentos en cada medio que coinciden con su forma de interpretar el recorte de recursos a las universidades federales. Según Ancelovici (2002, p. 434), “[...] nuevos frames interpretativos no se inventan simplemente de la nada. Se basan en valores familiares, categorías y símbolos, y es esta familiaridad que les permite resonar con el público objetivo".

\section{Conclusiones}

En definitiva, la aceptación de frames de medios por parte del público de Folha Online y Estadão.com, al tomar en consideración el uso de palabras clave en sus publicaciones en Twitter, mostró puntos de concordancia para definir la situación. En las variables agentes causales y, en menor medida, en las evaluaciones morales, fue más difícil encontrar coincidencias en el uso de palabras clave en las opiniones de los usuarios en los tuits. A priori, postulamos que este contexto beneficiaría la adopción de frames que explicarían, principalmente, las evaluaciones morales, pero esto fue rechazado, 
porque, aunque hay puntos en común, las lecturas y perspectivas de los usuarios de Twitter fueron diferentes, lo que evidencia la naturaleza plural de los marcos que circulan dentro de la plataforma.

Por lo tanto, un estudio de este tipo no puede ser únicamente atendido a partir de los marcos de los medios, sino que debe también reconocer la acción de frames de otro tipo de agentes. En ello, la propuesta de una metodología de este artículo cobra importancia dentro del esfuerzo por abordar un espacio de trabajo tan dinámico como Twitter. En especial frente a contextos impregnados de afectos políticos.

Aunque, el resultado permitió identificar una coincidencia en la proporción de uso de palabras según las funciones en cada medio. Es decir, el grupo de palabras con más repeticiones en un medio fue el más repetido en el otro, aun siguiendo porcentajes diferentes. Este estudio no encontró similitudes contundentes entre ambos periódicos y sus audiencias. Sin embargo, podemos considerar relevante la forma en que se abordó la discusión en las conversaciones de las dos audiencias en Twitter. Es decir, la interpretación causal fue el tipo de función más utilizada en todas las relaciones establecidas, lo que significa que, en la etapa inicial analizada de la situación, la opinión se centró más en la búsqueda de los responsables de la medida.

Aunque los números no prueban una correspondencia entre los medios y el público, el comportamiento general de la función evaluación moral en relación con los otros adoptados en cada prueba permite observar que la discusión fue variada. Por lo tanto, medir con palabras clave no permitiría encontrar relaciones tan significativas. Las investigaciones futuras para evaluar cuestiones morales pueden utilizar, por ejemplo, los principales hashtags en controversias políticas como variables.

Como limitación metodológica y para llevar a cabo una prueba más precisa, de acuerdo con el estado general de la discusión, es necesario, en futuras investigaciones, recopilar datos en un período superior a dos meses para controlar la evolución de la adhesión de los frames por parte de la audiencia y para verificar si también hubo cambios de opinión, además de cruzar datos de otros periódicos y contemplar una muestra de audiencia más amplia. Aun así, sería interesante considerar las palabras clave como un elemento central en al menos tres de las funciones indicadas por Entman, ya que las publicaciones de Twitter representan un desafío metodológico para la identificación de las relaciones de encuadramiento. De hecho, la mayoría de los motores de búsqueda de Twitter funcionan a partir de unidades de análisis como palabras clave, hashtags o nombres de usuario, por lo que entendemos que estos son los mejores elementos para buscar relaciones sólidas en este tipo de investigación.

Vale decir que nuestro estudio no consideró algunas variables que podrían haber alterado el resultado, como la ubicación de los usuarios y los tuits que no usan los filtros en la herramienta TweetDeck y que aún se ocuparon del tema. Además, otros elementos en algunos de los tuits no fueron considerados en la investigación, lo que pudo intervenir en las conclusiones del estudio. Por ejemplo, el uso de gifs, memes y fotografías por parte de los medios de comunicación que complementarían la perspectiva sobre el tema e incluso darían otro contexto a ciertas palabras y a los posts publicados por los periódicos. Estas unidades de análisis también servirían a una interpretación específica que, como mencionamos, escapó de nuestro enfoque. Sería interesante examinarlos en otros estudios sobre el tema para identificar si actúan como reforzadores de los frames. 
Por otro lado, es importante destacar que los estudios sobre media effects están estrechamente ligados a los avances tecnológicos, por lo que avanzar hacia la consolidación de conceptos y la delimitación de hipótesis facilita la tarea de llevarlos al campo empírico. Precisamente, al observar que el framing en las redes sociales es mucho más inmediato, el estudio sobre la aceptación de estos frames puede alcanzar nuevos territorios si se consideran los elementos (no periodísticos) presentes en un espacio como Twitter. La arena política brasileña mostró similitudes con otros movimientos políticos a gran escala, lo que sirve para reforzar dos puntos: (a) que los frames mediáticos que adopta un individuo están directamente relacionado con el nivel de información e importancia que esa persona da a una cuestión y (b) que los frames recurrentes pueden propagar información sesgada y, a menudo, descontextualizada, lo que contribuye a la polarización política y la desinformación. Si aceptamos la idea de Twitter como espacio de diálogo y construcción de opinión pública, admitimos la presencia de varios actores. A manera de reflexión, proponemos repensar la perspectiva mediocéntrica del framing en Twitter, precisamente por mostrarse insuficiente para abarcar la influencia y convergencia de actores políticos y audiencias heterogéneas.

\section{Referencias bibliográficas}

Almeida, M. L. N. de. (1993). Folhas ao vento: análise de um conglomerado jornalístico no Brasil. RAE-Revista de Administração de Empresas, 33(4), 106-107. Recuperado de http://dx.doi.org/10.1590/S0034-75901993000400010

Ancelovici, M. (2002). Organizing against globalization: the case of ATTAC in France. Politics \& Society, 30(3), 427-463.

Akhavan M. R., \& Ramaprasad, J. (2000). Framing Beijing: dominant ideological influences on the american press coverage of the Fourth UN Conference on Women and the NGO Forum. International Communication Gazette, 62(1), 45-59. https:// doi.org/10.1177/0016549200062001004

Bonone, L. M. (2017). Construção de método para pesquisas de Frame Analysis. Estudos em Jornalismo e Mídia, 13(2), 78-87.

Bronstein, C. (2005). Representing the third wave: mainstream print media framing of a new feminist movement. Journalism \& Mass Communication Quarterly, 82(4), 783-803.

Brüggemann, M. (2014). Between frame setting and frame sending: how journalists contribute to news frames. Communication Theory, 24(1), 61-82.

Callaghan, K.,\&Frauke, S. (2001) Assessing the democratic debate: how the news media frame elite policy discourse, political communication, 18(2), 183-213. https://doi.org/10.1080/105846001750322970

Cappella, J. N., \& Jamieson, K. H. (1997). Spiral of cynicism: the press and the public good. Nova York/Oxford: Oxford University Press.

Carragee, K. M.,\& Roefs, W. (2004). The neglect of power in recent framing research. Journal of Communication, 54(2), 214-233. 
Chong, D.,\& Druckman, J. N. (2007). A theory of framing and opinion formation in competitive elite environments. Journal of Communication, 57(1), 99-118.

Colling, L. (2001). Agenda-setting e o framing: reafirmando os efeitos limitados. Famecos, 14, 88-101.

Denzin, N. K. Lincoln, Y. S. (2006). O planejamento da pesquisa qualitativa: teorias e abordagens. Porto Alegre: Grupo A.

De Vreese, C. H. (2005). News framing: theory and typology. Information Design Journal \& Document Design, 13(1), 51-62.

D’Angelo, P.,\&Kuypers, J. A. (2010). Introduction: doing news framing analysis. In D’Angelo, P.,\&Kuypers, J. A. (Eds.). Doing news framing analysis: empirical and theoretical perspectives (p. 1-13). Nova York: Routledge.

D'Angelo, P. 2002News framing as a multiparadigmatic research program: A response to Entman. Journal ofcommunication, 52(4), 870-888.

Druckman, J. N. (2001). Evaluating framing effects. J. Econ. Psychol, 22, 91-101.

Entman, R. M. (1993). Framing: toward clarification of a fractured paradigm. Journal of Communication, 43(4), 51-58.

Eyal, C. H.,Winter, J. P., \& Degeorge, W. F. (1981). The concept of time framing in agenda-setting. In:Wilhoit, G. C. (Ed.), Mass Communication Review Yearbook: v. 2 (p. 212-217). Beverly Hills: Sage.

França, V.R.V. (2012). Discutindo o modelo praxiológico da comunicação- controvérsiase desafios da análise comunicacional. Porto Alegre: Sulina.

Gamson, W.,\&Modigliani, A. (1989). Media discourse and public opinion on nuclear power: a constructionist approach. American Journal of Sociology, 95(1), 1-37.

Goffman, E. (2012). Os quadros da experiência social: uma perspectiva de análise. Petrópolis: Vozes.

Goffman, E. (1986). Frame analysis: an essay on the organization of experience. Northeastern University Press.

Koenig, T. (2004). On frame and framing: anti-semitism as free speech: a case study. In: Encontro Anual do IAMCR, Porto Alegre, RS.

Latinobarómetro. (2018). Informe 2018. Santiago, Chile: Corporación Latinobarómetro, 2018. Recuperado el 24 agosto, 2019, de http://www.latinobarometro.org/latdocs/INFORME_2018_LATINOBAROMETRO.pdf.

Leal, P. M. V. (2007). News frames no jornalismo político brasileiro: análise de enquadramento da cobertura do escândalo dos Sanguessugas. En: Congresso Brasileiro de Ciências da Comunicação, 30, Santos, SP. CD-ROM.

López Rabadán, P. (2010). Nuevas vías para el estudio del framing periodístico. La noción de estrategia de encuadre. Estudios Sobre El Mensaje Periodístico, 16, 235-258. Recuperado de: https://revistas.ucm.es/index.php/ESMP/article/ view/ESMP1010110235A

McCombs M., \&Reynolds, A. (2002). News influence on our pictures of the world. In Bryant, J., \& Zillmann, D. (Eds.), LEA's communication series. Media effects: Advances in theory and research (p. 1-18). Mahwah, NJ, US: Lawrence Erlbaum Associates Publishers. 
Newman, N., Fletcher, R.,Kalogeropoulos, A., \& Nielsen, R. K. (2019). Reuters Institute Digital News Report. Oxford: Reuters Institute for the Study of Journalism.

Oliveira, M. F. de. (2011). Metodologia científica: um manual para a realização de pesquisas em Administração. Catalão, GO: Universidade Federal de Goiás. Recuperado em 24 agosto, 2019, de https://adm.catalao.ufg.br/up/567/o/Manual_ de_metodologia_cientifica_- Prof_Maxwell.pdf

Valera Ordaz, Lidia. Zer 21(41) : 13-31 (2016). URI. http://hdl.handle.net/10810/41231. El sesgo mediocéntrico del “framing” en España: una revisión crítica de la aplicación de la teoría del encuadre en los estudios de comunicación

Park, J. (2003). Contrasts in the coverage of Korea and Japan by US television networks: a frame analysis. International Journal for Communication Studies, 65(2), 144-164.

Porto, M. P. (1999). Interpretando o mundo da política: perspectivas teóricas no estudo da relação entre psicologia, poder e televisão. In: Encontro Anual da Associação Nacional de Pós-graduação e Pesquisa em Ciências Sociais (ANPOCS), 13, Caxambu, MG. Anais... Caxambu, MG.

Porto, M. P. (2004). Enquadramentos da mídia e política. En: Rubim, A. A. C. (Org.), Comunicação e política: conceitos e abordagens (pp. 73-104). Salvador: Edufba.

Pozobon, R.,\& Schaefer, R. (2014). Perspectivas contemporâneas sobre as pesquisas de enquadramento: uma proposta de sistematização conceitual. Revista Fronteiras, 16(3), 157-168.

Rossetto, G. P. N., \& Silva, A. M. (2012). Agenda-setting e framing: detalhes de uma mesma teoria? Intexto, (26), 98-114.

Scheufele, D. A. (1999). Framing as a theory of media effects. Journal of Communication, 49(1), 103-122.

Scheufele, D. A. (2000). Agenda-setting, priming and framing revisited: another look at cognitive effects of political communication. Mass Communication \& Society, 3(2\&3), 297-316.

Shah, D.V., Kwak, N.,\& Holbert, R.L. (2001). 'Connecting' and 'disconnecting' with civic life: patterns of Internet use and the production of social capital. Political Communication, 18(2), 141-162.

Teixeira, A. V. (2017). Contribuições da análise do enquadramento noticioso para as pesquisas em comunicação. Temática, (13). Recuperado el 24 agosto, 2019, de 10.22478/ufpb.1807-8931.2017v13n5.34307.

Wolf, M., 2012. Teorias da comunicação. 6th ed. Lisboa: martins fontes, p.75.

Zhou, Y.,\& Moy, P. (2007). Parsing framing processes: the interplay between online public opinion and media coverage. Journal of Communication, 57(1), 79-98. 
Apéndice A. Palabras clave que aparecieron en cada función al menos dos veces

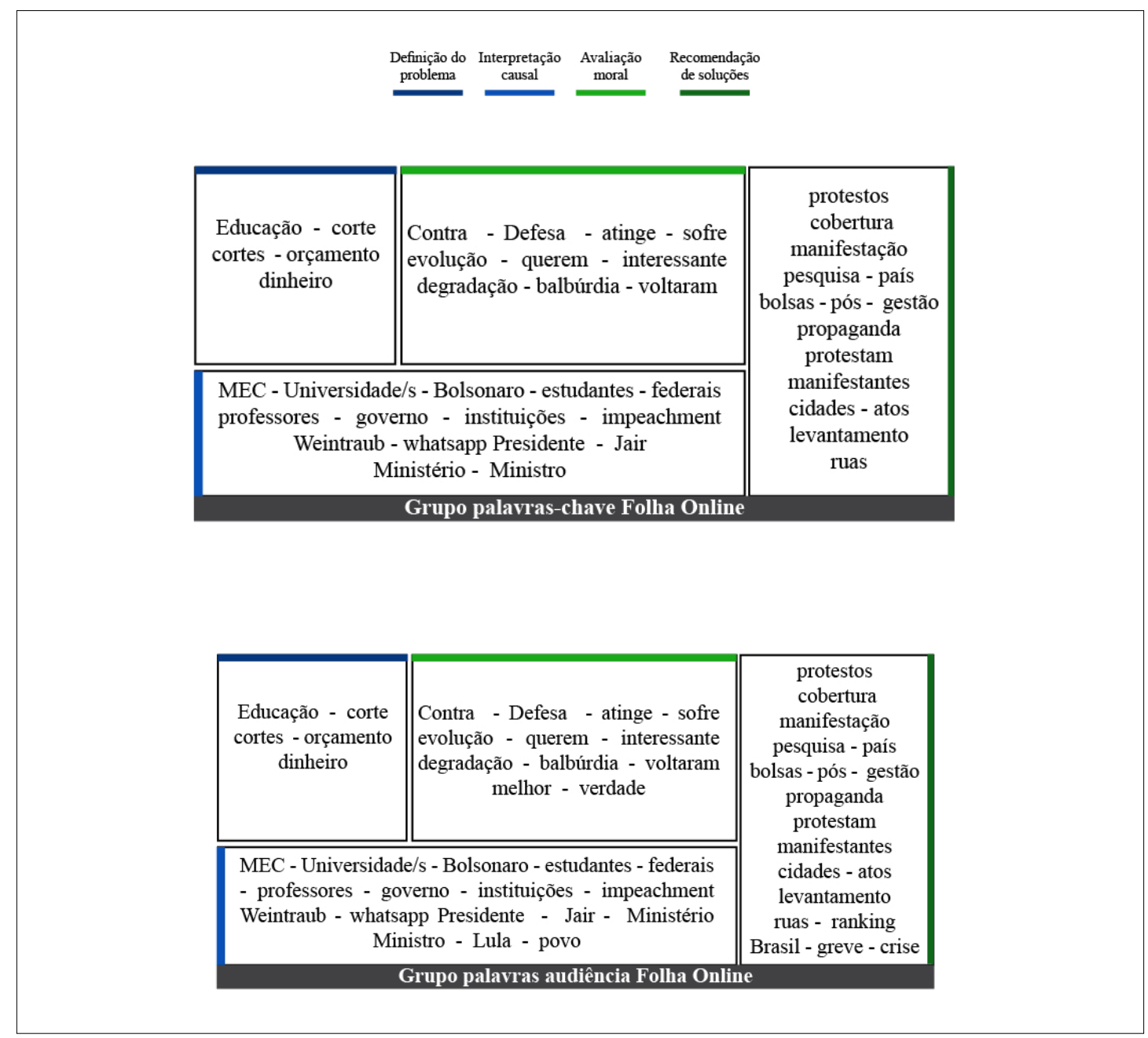


Frames en 280 caracteres: un estudio sobre el proceso de incorporación de los marcos propuestos...

Educação - corte

cortes - bloqueios

verbas - orçamento

verba - suspensão

dinheiro - recursos

cortará - redução medida
Contra - não - defende - defesa - propaganda - atinge atingir - suspensão - sofra - evolução - custeio - querem interessante - degradação - balbúrdia - melhor - úteis levantamento - promovidos - verdade - boato - idiotas oposição - confronto - contingenciamento - bagunça ridículo - inspiração

MEC - Bolsonaro - universidade/s - estudantes - país federais - federal - Ministro

pesquisa - governo - instituiçao - repassadas repasses - Presidente - Brasil

protesto/s - cobertura manifestação - bolsas gestão - protestam atos - levantamento ruas - paralisação juíza - congresso

Grupo palavias-chave Estadão.com

\begin{tabular}{|c||c|}
\hline $\begin{array}{c}\text { Educação - corte } \\
\text { cortes - verbas } \\
\text { orçamento } \\
\text { verba - dinheiro }\end{array}$ & $\begin{array}{c}\text { Contra - não - balbúrdia - melhor } \\
\text { contingenciamento - bagunça }\end{array}$ \\
\hline $\begin{array}{c}\text { MEC - Bolsonaro - universidade/s - estudantes - país } \\
\text { federais - federal - professores - alunos - Ministro } \\
\text { pesquisa - governo - instituições - instituiçao - repassadas } \\
\text { repasses - Weintraub - Presidente - Jair - Ministério - Brasil }\end{array}$ \\
\hline Grupo palaviras audiência Estadão.com
\end{tabular}

Grupo palavras audiência Estadão.com 